\title{
THEORETICAL FLEXURAL BEHAVIOR OF SANDWICH PANEL USING COMPOSITE MATERIALS
}

\author{
Dipak D. Bari ${ }^{1}$, P.S.Bajaj ${ }^{2}$ \\ ${ }^{1}$ PG Student, Department of Mechanical Engineering, SSGBCOE\&T Bhusawal, NMU Jalgaon; Maharashtra, India \\ ${ }^{2}$ Professor, Department of Mechanical Engineering, SSGBCOE\&T Bhusawal, NMU Jalgaon; Maharashtra, India
}

\begin{abstract}
Sandwich panels made of thin polymer composite materials have been developed and characterized as an alternative material to the mild steel sheet sheets conventionally used as face sheet materials [outer cover] for refrigerator, washing machine, and in automotive appliances like automobile, boat etc. In this paper sandwich panel made of Glass Chopped Strand Mat (GCSM) face sheets with polyester foam Coremat XM, polyester foam Coremat Xi and jute are fabricated. Flexural behavior of sandwich panel is studied. Theoretical results of sandwich panel is compared with $0.8 \mathrm{~mm}$ M.S. specimen conventionally used for manufacturing the body of automobile, cover of many machines and appliances. The load versus deflection relation of sandwich panel is almost linear. The strength and deflection are calculated theoretically by the equations derived from theory of bending. From the results It is found that sandwich composite have quite superior properties, which can be used for various engineering applications.
\end{abstract}

Keywords - Glass Chopped Strand Mat [GCSM], Polyester Coremat foam, Sandwich, Flexural.

\section{INTRODUCTION}

Composite material means consisting of two or more distinct phases.Thus the material having two or more distinct constituints, having dictinct interface seperating them are called as composite materials.Polymer composite are important class of composite materials in which polymers are reinforced by stiff and high strenght fibers. They have proven properties in number of engineering fields such as aerospace,automotive and civil engineering. Reason for their getting more popular day-by-day is that they accommodate desirable properties like lightweight,high stiffness to weight and strength to weight characteristics and good corrosion resistance.

Sandwich structures are found to be most in case of high specific bending stiffness and strength.A sandwich is three layer structure made up of an upper and lower face sheets (skins) and core in between them which are bonded together as shown in figure 1.The face sheet carries in plane loads, while the core maintains a distance between face sheets. The face sheets can be made of isotropic or anisotropic materials such as metal sheets and FRP laminates respectively.

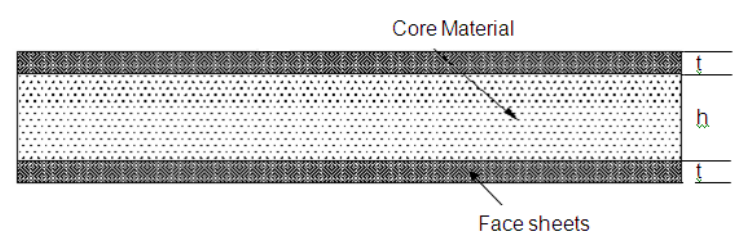

Fig 1 Sandwich composite structure
For isotropic materials like metals, I-beam is an efficient structural shape as most of the material is placed in the flanges situated farthest from the center of bending and neutral axis. In sandwich panels, the facesheets are equivalent as the flanges and the core acts as the web. In bending of beams, the lower face sheet is in tension, while the upper face sheet is in compression, and the core is mainly loaded in shear.

When a sandwich panel is subjected to transverse load, a bending moment acts on the panel, which creates tensile and compressive stresses in the skins and shear stresses in the core. The sandwich panel should be strong enough to bear these stresses. Thus, the behavior of the sandwich panel in bending is considered to be critical for intended applications of thin polymer composites. Thin sandwich panel sheets are designed to be stiff, strong, light weight in comparison of mild steel (MS) sheets of thickness ranging between 0.7 to $1.0 \mathrm{~mm}$. MS sheets of such thickness are usually employed for making auto bodies and the covers of many other machines and appliances.

\section{FABRICATION PROCESS}

Sandwich panels are fabricated from which specimen are cut in required sizes depending on the test being performed. For fabricating a single sandwich panel core material and GCSM materials are cut in to pieces of $350 \mathrm{~mm} \times 400 \mathrm{~mm}$ size. The epoxy is mixed with $10 \%$ hardener thoroughly. Sandwich panels are fabricated using the hand layup process and are cured in between two glass plates for 48 hours at room temperature. 


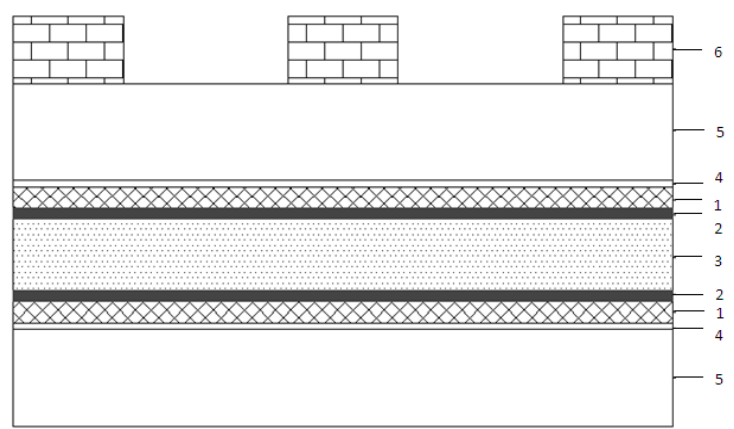

Fig 2 Fabrication process: symmetric Lay-up

1. Woven Glass fabric

2. Glass Chopped Strand Mat fiber

3. Core material (J-CORE, Xi-CORE, XM-CORE)

4. Thin Mylar sheet

5. Glass plate

6. Bricks

For fabricating a sandwich panel, over the bottom glass plate, a thin Mylar sheet is placed which works as release sheet as the epoxy does not stick to it. A thin layer of resin is then applied on this Mylar sheet by a brush. Then one layer of woven glass fabric is placed on the resin layer. A thick layer of resin is applied on the fabric sheet to wet the fibers completely, followed by a layer of GCSM. Then one layer of a core material (Jute, Coremat Xi, or Coremat XM is placed on this layer and rolled by using a roller. This ensured that the resin is uniformly spreaded over whole layer. Then a core material is impregnated with resin. Then, the upper CSM and upper face sheet reinforcement sheet is placed and resin is brushed over it. The assembly is rolled to remove excess resin. The top Mylar sheet and glass plates are placed. Over the glass plate, some bricks (Total weight $\approx 52 \mathrm{Kg}$ ) are laid to develop a light pressure. In this manner following three type os sandwich panels are fabricated.

1. Panel 01- CSM fiber is used as outer and inner face sheets. Polyester foam Coremat XM / epoxy is treated as a core a material (CSM/XM/CSM).

2. Panel 02- CSM fiber is used as outer and inner face sheets. Polyester foam Coremat $\mathrm{Xi} /$ epoxy is treated as a core material (CSM/Xi/CSM).

3. Panel 03- CSM fiber is used as outer and inner face sheets. Jute fabric / epoxy is treated as a core material $(\mathrm{CSM} / \mathrm{J} / \mathrm{J} / \mathrm{CSM})$.

\subsection{Specimen Geometry}

Static flexural behavior of thin sandwich panel has been studied using a three-point flexural test. In this study, a threepoint bend specimen is used with a span length of $62 \mathrm{~mm}$. The three-point flexural test has been carried out on the sandwich specimen of dimensions $90 \mathrm{~mm} \times 20 \mathrm{~mm}$ as shown in Figure 3.

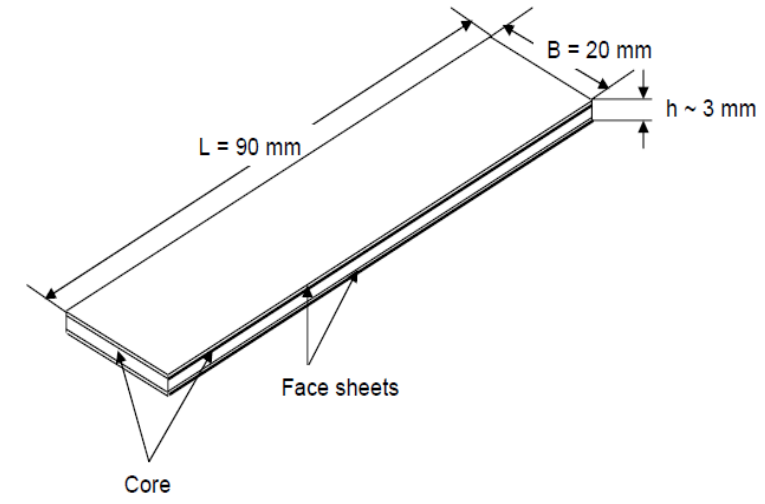

Fig 3 Geometry for the 3-point flexural test

\section{THEORETICAL ANALYSIS}

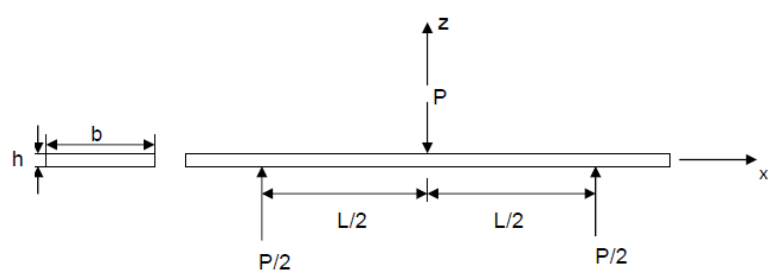

Fig 4 3-point flexural tests (Schematic)

Bending stress and deflection equations are developed from simple theory of plate bending. Bending stress at a point of the sandwich panel is given by,

$$
\sigma_{x x}=\frac{z_{x} P L\left(D_{22}-v_{y x} D_{12}\right)}{4\left(1-v_{x y} v_{y x}\right)\left(D_{11} D_{22}-D_{12}^{2}\right) B}
$$

and the deflection $\mathrm{w}$ at the midpoint of the 3-point bend specimen is

$$
w=\frac{D P L^{3}}{48 B}
$$

Where,

$\mathrm{B}$ : width of the specimen

$\mathrm{L}$ : length between the supporting rollers

$\mathrm{P}$ : the center load

Dij : the components of bending stiffness matrix [ Agarwal and Broutman, 1990]

vij : the Poisson's ratio

Ex: the elastic modulus of outer face sheet

$\mathrm{z}$ : the distance from the mid plane. 


\section{RESULTS AND DISCUSSION}

Different sandwich panels are developed by using Glass chopped strand mat (GCSM).Three kinds of core materials such as polyester foam Coremat $\mathrm{Xi}$, polyester foam Coremat $\mathrm{XM}$, and Jute fabric are used with each type of face sheet for developing different kinds of sandwich panels. The results of sandwich panels are compared with that of $0.8 \mathrm{~mm}$ thick MS Sheet, conventionally used for manufacturing the body of automobile, cover of many machines and appliances. Section 4.1 discusses about the conventional mild steel material for the cover of machines and appliances. Section 4.2 discusses about $\mathrm{CSM} / \mathrm{Xi} / \mathrm{CSM}$ thin sandwich panel. Section 4.3 discusses about CSM/XM/CSM thin sandwich panel and Section 4.4 discusses $\mathrm{CSM} / \mathrm{J} / \mathrm{J} / \mathrm{CSM}$ thin sandwich panel. Section 4.5 compares flexural stiffness of all kinds of thin sandwich panels and conventional material; Also flexural strength of sandwich panels was reported.

\subsection{Mild Steel Sheet}

Mild steel yields at a very early stage of the midpoint deflection less than $1 \mathrm{~mm}$. It then plastically deforms and work hardens. Load vs. deflection relation for $0.8 \mathrm{~mm}$ thick MS sheet is as shown in Figure 5, conventionally used in manufacturing the auto outer body.

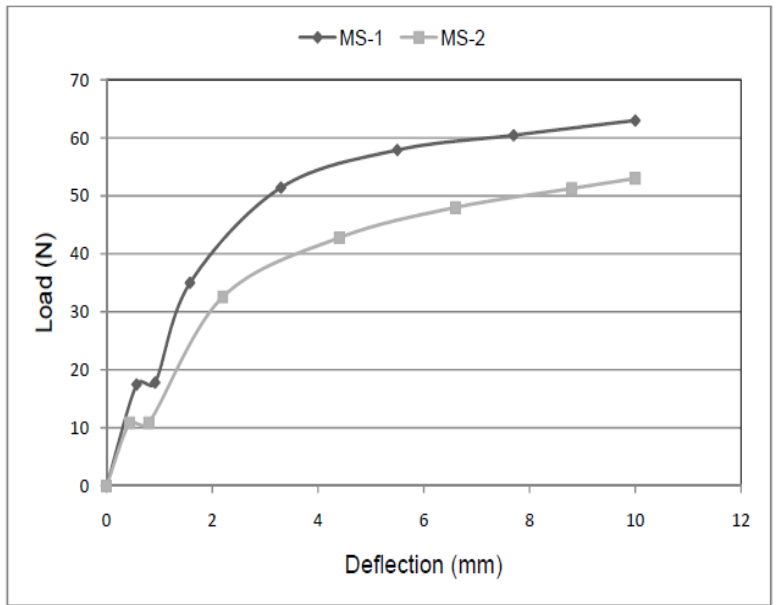

Fig 5 Load vs. deflection curve for $0.8 \mathrm{~mm}$ thick MS specimens

To compare various thin sandwich panels with $0.8 \mathrm{~mm}$ thick MS Sheet, the flexural stress and center deflection of $0.8 \mathrm{~mm}$ thick MS sheet are calculated from simple theory of plate bending. The calculations are done at a load up to yielding and their details are listed in Table 1. The flexural failure of the mild steel plate specimen takes place due to the yielding because all the points on the cross section of the plate are not uniformly stressed.

Table-1 Theoretical center deflections and Theoretical flexural stresses for $0.8 \mathrm{~mm}$ thick MS plate Specimens

\begin{tabular}{|c|c|c|c|c|}
\hline Specimen No. & $\begin{array}{c}\text { Load up to } \\
\text { yielding }(\mathbf{N})\end{array}$ & $\begin{array}{c}\text { Thickness } \\
(\mathbf{m m})\end{array}$ & $\begin{array}{c}\text { Deflection }\left[\mathbf{w}_{\mathbf{z}}\right] \text { at the } \\
\text { center }(\mathbf{m m})\end{array}$ & $\boldsymbol{\sigma}_{\mathbf{x x}}(\mathbf{M P a})$ \\
\hline MS-1 & 17.5 & 0.8 & 0.5077 & 127.1 \\
\hline MS-2 & 10.9 & 0.8 & 0.3162 & 79.19 \\
\hline
\end{tabular}

\subsection{CSM/Xi/CSM Sandwich Panel}

Following table reports theoretical center deflections and theoretical flexural stresses for CSM/Xi/CSM specimen. Compare to MS specimen load is considered up to yielding and for all sandwich panels peak load is considered for this study. [9].

Table-2 Theoretical center deflections and Theoretical flexural stresses for CSM/Xi/CSM specimen

\begin{tabular}{|c|c|c|c|c|}
\hline Specimen & Thickness & Peak Load & $\begin{array}{c}\text { Deflection }(\mathbf{w z}) \mathbf{a t} \\
\text { peak load }(\mathbf{m m})\end{array}$ & $\left(\boldsymbol{\sigma}_{\mathbf{x x}}\right) \mathbf{M P a}$ \\
\hline $\mathrm{CSM} / \mathrm{Xi} / \mathrm{CSM}$ & 3.43 & 309 & 4.1406 & 158.2 \\
\hline $\mathrm{CSM} / \mathrm{Xi} / \mathrm{CSM}$ & 3.46 & 298 & 3.9356 & 151.1 \\
\hline $\mathrm{CSM} / \mathrm{Xi} / \mathrm{CSM}$ & 3.25 & 285 & 4.4061 & 159.0 \\
\hline $\mathrm{CSM} / \mathrm{Xi} / \mathrm{CSM}$ & 3.45 & 300 & 3.9900 & 152.8 \\
\hline
\end{tabular}




\subsection{CSM/XM/CSM Sandwich Panel}

Table-3 Theoretical center deflections and Theoretical flexural stresses for CSM/XM/CSM specimen

\begin{tabular}{|c|c|c|c|c|}
\hline Specimen & Thickness & Peak Load & $\begin{array}{c}\text { Deflection }\left(\mathbf{w}_{\mathbf{z}}\right) \mathbf{a t} \\
\text { peak load }(\mathbf{m m})\end{array}$ & $\left(\boldsymbol{\sigma}_{\mathbf{x x}}\right) \mathbf{M P a}$ \\
\hline $\mathrm{CSM} / \mathrm{XM} / \mathrm{CSM}$ & 3.50 & 299 & 3.8810 & 150.8 \\
\hline $\mathrm{CSM} / \mathrm{XM} / \mathrm{CSM}$ & 3.46 & 207 & 2.7634 & 106.9 \\
\hline $\mathrm{CSM} / \mathrm{XM} / \mathrm{CSM}$ & 3.20 & 242 & 3.9276 & 140.6 \\
\hline $\mathrm{CSM} / \mathrm{XM} / \mathrm{CSM}$ & 3.33 & 240 & 3.5256 & 131.3 \\
\hline
\end{tabular}

\subsection{CSM/J/J/CSM Sandwich Panel}

Table-4 Theoretical center deflections and Theoretical flexural stresses for CSM/J/J/CSM specimen

\begin{tabular}{|c|c|c|c|c|}
\hline Specimen & Thickness & Peak Load & $\begin{array}{c}\text { Deflection }\left(\mathbf{w}_{\mathbf{z}}\right) \text { at } \\
\text { peak load }(\mathbf{m m})\end{array}$ & $\left(\sigma_{\mathrm{xx}}\right) \mathbf{M P a}$ \\
\hline CSM/J/J/CSM & $\mathbf{3 . 0 0}$ & 415 & $\mathbf{7 . 4 2 4 3}$ & $\mathbf{2 4 7 . 1}$ \\
\hline CSM/J/J/CSM & $\mathbf{2 . 9 6}$ & $\mathbf{3 8 2}$ & $\mathbf{7 . 0 8 6 1}$ & $\mathbf{2 3 2 . 7}$ \\
\hline CSM/J/J/CSM & $\mathbf{2 . 9 6}$ & $\mathbf{3 6 5}$ & $\mathbf{6 . 7 7 0 7}$ & $\mathbf{2 2 2 . 3}$ \\
\hline CSM/J/J/CSM & $\mathbf{2 . 9 6}$ & $\mathbf{4 0 0}$ & $\mathbf{7 . 4 2 0 0}$ & $\mathbf{2 4 3 . 6}$ \\
\hline
\end{tabular}

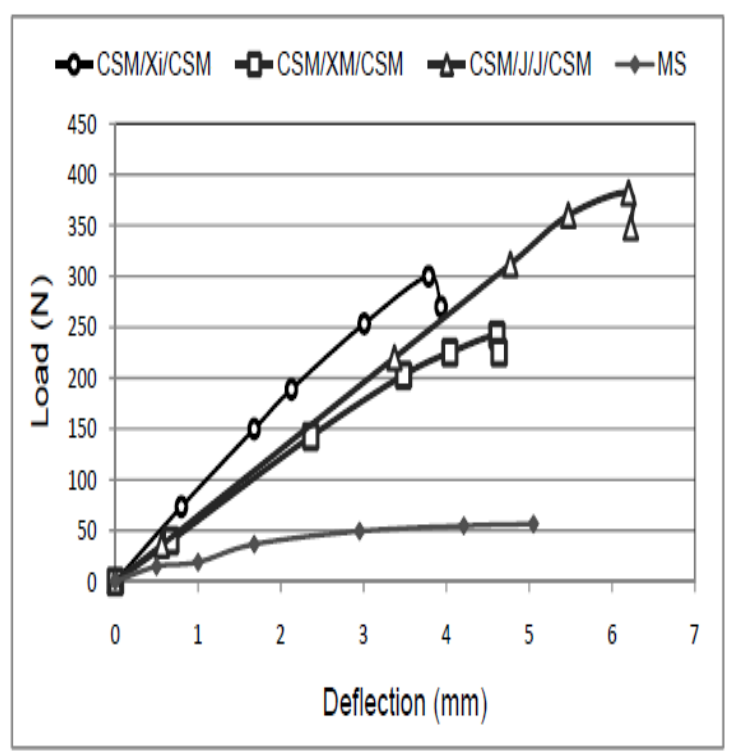

Fig 6 Comparison of load vs. deflection curves of Chopped Strand Mat (CSM) fiber face sheets based thin sandwich specimens with $0.8 \mathrm{~mm}$ thick MS sheet

Flexural strength of sandwich panels with GCSM face sheets is 1.38 times greater than that of yield strength of MS sheet. From above figure, it can be concluded that thin sandwich specimens are having load bearing capacity and flexural stiffness as intermediate in case of CSM fiber face sheets as compared to $0.8 \mathrm{~mm}$ thick MS sheet.

\subsection{Flexural Stiffness of Sandwich Panels}

For a sandwich panel, the flexural stiffness is a very important parameter under flexural loading. Greater the flexural stiffness a panel has, lesser is the deflection of the panel. Thus, in the designs where the deflection of the panel is required to be restricted, the flexural stiffness is taken into consideration.

$$
D=\frac{P L^{3}}{48 B w}
$$

Where,

$\mathrm{D}$ is the flexural stiffness in MPa-mm3

$\mathrm{P}$ is the Experimental load in $\mathrm{N}$

$\mathrm{L}$ is the distance between supporting rollers in $\mathrm{mm}$

$B$ is the width of a specimen in $\mathrm{mm}$

$\mathrm{w}$ is the Experimental deflection in $\mathrm{mm}$

The flexural stiffness of various kinds of sandwich panels are compared with $0.8 \mathrm{~mm}$ thick MS sheets which are conventionally employed in manufacturing the car outer body. The average flexural stiffness of specimens of each kind of sandwich panel is reported in Table 5. 
Table-5 flexural stiffness of various thin sandwich specimens and $0.8 \mathrm{~mm}$ thick MS sheet

\begin{tabular}{|c|c|c|c|c|}
\hline Specimen & $\begin{array}{c}\text { Avg. } \\
\text { Thickness } \\
(\mathbf{m m})\end{array}$ & $\begin{array}{c}\text { Avg. } \\
\text { Peak } \\
\text { load (N) }\end{array}$ & $\begin{array}{c}\text { Avg. } \\
\text { Theoretical } \\
\text { Deflection } \\
(\mathbf{m m})\end{array}$ & $\begin{array}{c}\text { Avg. } \\
\text { Flexural } \\
\text { stiffness } \\
\text { (GPa-mm3) }\end{array}$ \\
\hline $\mathrm{CSM} / \mathrm{Xi} / \mathrm{CSM}$ & 3.40 & 298 & 4.1203 & 21.20 \\
\hline $\mathrm{CSM} / \mathrm{XM} / \mathrm{CSM}$ & 3.37 & 247 & 3.5244 & 16.12 \\
\hline $\mathrm{CSM} / \mathrm{J} / \mathrm{J} / \mathrm{CSM}$ & 2.97 & 390.5 & 7.1752 & 17.54 \\
\hline $\mathrm{MS}$ & 0.8 & 17.5 & 0.4119 & 7.627 \\
\hline
\end{tabular}

From above, it can be concluded that various thin sandwich specimens are having load bearing capacity and flexural stiffness as intermediate in case of CSM fiber face sheets, as compared to $0.8 \mathrm{~mm}$ thick MS sheet.

\section{CONCLUSIONS}

In this study high strength ,high stiff GCSM face sheets are fabricated with a Polyster foam coremat and jute is used as a core material to form composite sandwich panel. The load versus deflection relation of all sandwich panels is almost linear. The strength and deflection are calculated theoretically by the equations derived from theory of bending. The flexural stiffness of sandwich panels is $2.5-3.5$ times the $0.8 \mathrm{~mm}$ thick MS Sheet. While, the flexural strength of sandwich panels is $1-2$ times the $0.8 \mathrm{~mm}$ thick MS Sheet.

\section{REFERENCES}

[1]. Agarwal B. D. and Broutman L.J., [1990], Analysis and Performance of fiber composites, Second Edition, John Wiley \& Sons Inc., New Jersey, pp.188-198.

[2]. Botelho E. C., Figiel, Rezende M.C. and Lauke B., [2003], Mechanical behavior of carbon fiber reinforced polyamide composites, Composites Science and Technology, Volume 63, Issue 13, Pages 1843-1855.

[3]. Bhadauria A. S., [2007], Characterization of Thin Sandwich Panel Made of GFRP Skin and Cotton Fabric Core, M. Tech. Thesis, Department of Mechanical Engineering, IIT Kanpur, India.

[4]. Dai J. and Hahn H.T., [2003], Flexural behavior of sandwich beams fabricated by vacuum assisted resin transfer molding, Composite Structures, Volume 61, Issue 3, Pages 247-253.

[5]. Dweib M.A., Hu B., O'Donnell A., Shenton H.W. and Wool R.P., [2004], All natural composite sandwich beams for structural applications, Composite Structures, Volume 63, Issue 2, Pages 147-157.

[6]. Davolos J.F., Qiao P., Xu X.F., Robinson J., Karl E, Barth, [2001], Modelling and characterization of fiberreinforced plastic honeycomb sandwich panels for highway bridge applications, Composite Structures, Volume 52, Pages 441-452.
[7]. Feraboli P. and Masini A., [2004], Development of carbon/epoxy structural Components for a high performance vehicle, Composites Part B: Engineering, Volume 35, Issue 4, Pages 323-330.

[8]. Gaudenzi P., Pascucci A., Barboni R. and Horoschenkoff A., [1997], Analysis of a glassfibre sandwich panel for car body constructions, Composite Structures, Volume 38, Issues 1-4, pp. $421-433$.

[9]. A. Sharma [2011] "The Development Of Thin Sandwich Panels Made Of High Strength And High Stiffness Face Sheets And A Light Weight Core Material" Department of Mechanical Engineering, M.Tech. Thesis, COE,Pune, India. [10]. Mallick P.K., [1997], Composites Engineering Handbook, Marcel Dekker, New York.

[11]. Pahlajani V., July [2004], Design and Development of Light Weight automobile Panels with Sandwich Composite Materials (M.Des. Thesis, IIT Kanpur).

[12]. Sabeel K.A. and Vijayarangan S., [2008], Tensile, flexural and interlaminar shear properties of woven jute and jute glass fabric reinforced polyester composites, Journal of Materials Processing Technology, Volume 207, Issue 1-3, Pages 330-335.

[13]. Young W.C., [1989], Roark's Formulas for Stress and Strain, Handbook, Page 433.

[14]. V B Ugale, KK Singh, NM Mishra, Prashant Kumar.;December [2012] "Experimental studies on thin sandwich panels under impact and static loading" India.

[15]. V. B. Ugale, K. K. Singh,N.M. Mishra \& Prashant Kumar [2013], "Experimental and numerical study of carbon fabric reinforced thin sandwich panels under impact and static loading', presented at $4^{\text {th }}$ international conference on recent advances in composite materials

(ICRACM-2013), organized by IIT-BHU, Varanasi, February 18-21.

[16]. Prashant Kumar,V.BUgale,K K Singh and N M Mishra, "Flexural behavior of thin sandwich panels", ISAMPE National Conference on Composites, INCOMM 10, November 18-19, 2011, Pune, India.

[17]. Prashant Kumar,Axay Kumar \& Pankaj S. Chandel "Flexural properties of sandwich-panel made by using polyester coremat", Indo-Japan Joint Seminar on Manufacturing Science of Advanced Composites", February 21-26, 2005, IIT Kanpur. 